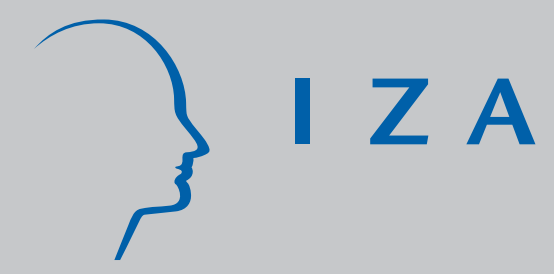

IZADP No. 1797

A Constitutional Theory of the Family

Alessandro Cigno

October 2005 


\title{
A Constitutional Theory of the Family
}

\author{
Alessandro Cigno \\ University of Florence, CESifo, CHILD \\ and IZA Bonn
}

Discussion Paper No. 1797

October 2005

\author{
IZA \\ P.O. Box 7240 \\ 53072 Bonn \\ Germany \\ Phone: +49-228-3894-0 \\ Fax: +49-228-3894-180 \\ Email: iza@iza.org
}

Any opinions expressed here are those of the author(s) and not those of the institute. Research disseminated by IZA may include views on policy, but the institute itself takes no institutional policy positions.

The Institute for the Study of Labor (IZA) in Bonn is a local and virtual international research center and a place of communication between science, politics and business. IZA is an independent nonprofit company supported by Deutsche Post World Net. The center is associated with the University of Bonn and offers a stimulating research environment through its research networks, research support, and visitors and doctoral programs. IZA engages in (i) original and internationally competitive research in all fields of labor economics, (ii) development of policy concepts, and (iii) dissemination of research results and concepts to the interested public.

IZA Discussion Papers often represent preliminary work and are circulated to encourage discussion. Citation of such a paper should account for its provisional character. A revised version may be available directly from the author. 
IZA Discussion Paper No. 1797

October 2005

\section{ABSTRACT}

\section{A Constitutional Theory of the Family}

The paper re-examines the idea that a family can be viewed as a community governed by a self-enforcing constitution, and extends existing results in two directions. First, it identifies circumstances in which a constitution is renegotiation-proof. Second, it introduces parental altruism. The behavioural and policy implications are illustrated by showing the effects of public pensions and credit rationing. These implications are not much affected by whether altruism is assumed or not, but contrast sharply with the predictions of more conventional models.

JEL Classification: C72, D02, D13, D71, D74, D91, H55, J13, J14

Keywords: families, self-enforcing constitutions, renegotiation-proofness, altruism, fertility, saving, transfers, attention, pensions, credit rationing

Corresponding author:

Alessandro Cigno

Dipartimento di Studi sullo Stato

Via delle Pandette 21

I-50127 Firenze

Italy

Email: cigno@unifi.it 


\section{Introduction}

"Economics is all about how people make choices; sociology is all about how they don't have any choices to make." (Duesemberry, 1960)

Intergenerational relations within the family are a case in point. Both the "unitary" and the "collective" economic models of the family assume individual optimization subject only to the law of the land. The sociology of the family, by contrast, stresses social constraints on individual behaviour. Reality lies somewhere in between these extremes. We do make individual choices about all kinds of things, including fundamental ones such a whether to maintain a relationship with our parents, and whether to marry and have children. But, if we do not cut our inherited links, or if we forge new ones, we implicitly make commitments that impose constraints on the allocation of our time, and on the use of our money. The tools of modern economic analysis allow us to simultaneously model the determination of family rules, and the choice of individual behaviour given those rules. The constitutional branch of modern political economy does in fact tell us that it may be in the interest of all members of a community to agree first on a constitution, allowing them to safely renounce the dominant strategy in a prisoner's dilemma type of situation, and then to optimize individually subject to that constitution.

Although originally conceived with reference to city or nation states, the constitution concept can be applied also to smaller groupings, such as extended families. Building on Shubick's (1981) notion of a threat equilibrium, Cigno (1993) puts forward the idea of a "family constitution", and establishes conditions under which this is self-enforcing in the sense that it supports a subgame-perfect Nash equilibrium. This approach is very different from that of Guttmann (2001) and others, who start from the hypothesis that parents can somehow make their children altruistic towards them. Both approaches aim to explain why some adults support their elderly parents, but one takes preferences as given, the other assumes that preferences can be manipulated.

Rosati (1996) adds uncertainty to the basic model. Cigno and Rosati (2000) introduce personal services without a perfect market substitute. Anderberg and Balestrino (2003) introduce education. The present paper extends the analysis in three directions. First, it identifies circumstances in which a family constitution is renegotiation-proof. That is important, because a constitution worth its name cannot be changed at will. Second, it explores the implications of introducing the intuitively appealing notion that parents are altruistic towards their chil- 
dren. Third, it shows how the model's behavioural implications differ from those of more conventional theories, in particular how the existence of family constitutions affects individual responses to policy.

The following assumptions and conventions will be used throughout the paper. The life cycle consists of three periods, labelled $t=0,1,2$. A person is said to be young in period 0 , an adult in period 1 , old in period 2. An adult can make money and have children. The young and the old can do neither. The young and the old are credit rationed, the former because they are not allowed to enter into legally binding contracts, the latter because they will not be around to pay back their debt, and will not allowed to leave a negative estate. To simplify matters, we shall reason as if reproduction occurred by parthenogenesis (hence the feminine gender), and suppose that, up to some physiological maximum, a woman can have as many children as she wants by bearing a fixed cost $p$ for every birth. We further assume that, given the parameters of the decision problem, the physiological maximum is never binding. These widely used assumptions are clearly unrealistic, but do not affect the points at issue in the present paper.

At any given date, a family will consist of individuals at different points of the life-cycle. These age differences are important, because they provide an opportunity for cooperation between members of the same family. Such an opportunity could arise also from differences of sex and other personal characteristics, but we assume those away to focus on intergenerational cooperation. Assuming that the economic environment is known with certainty and constant over time, we define a family constitution as a set of unwritten, typically unspoken, rules dictating (i) the minimum amount of money or personal services yielding the same utility, $z$, that an adult must transfer to each of her children, if she has any, and (ii) the minimum amount of money or personal services yielding the same utility, $x$, that the dame adult must transfer to her parent, conditional on the latter having obeyed the rules. The conditionality attached to (ii) makes it in every adult's interest to punish transgressors. That is important, because only an adult can punish another adult. Neither the young nor the old have the means to do so.

The existence of a family constitution gives each adult a choice of two strategies. One is to go it alone in the market (defect). The other is to comply (cooperate). Let $m_{0}$ be the sum of the money, and the money-equivalent of the personal services, that she gives each of her $n$ children when they are young, and $m_{1}$ the net amount she gives each of them when they become adults. A complier then faces the constraints

$$
n m_{0} \geq n z
$$


and

$$
n m_{1} \geq-n x,
$$

The first says that the complier cannot give a young child less than $z$. The second says that she cannot take more than $x$ from each of her grown-up children.

\section{The model with selfish agents}

In the present section, we make the standard economist's assumption (to be relaxed in section 3) that individuals are selfish. To begin with, we further assume that individuals derive utility only from market goods, and that the state of the world is known with certainty, and constant over time. Both these simplifying assumptions will be relaxed towards the end of the section.

A person's lifetime utility is given by

$$
U=u_{0}\left(c_{0}\right)+u_{1}\left(c_{1}\right)+u_{2}\left(c_{2}\right)
$$

where $c_{t}$ is consumption in period $t$, and the functions $u_{i}($.$) are increasing$ and concave, with $u_{i}^{\prime}(0)=\infty$.

\section{$2.1 \quad$ Go-it-aloners}

Will a selfish go-it-aloner have children? Since births are costly, and any children the agent might have would give her nothing when she gets old, she will have no children. For an adult with income $y$, the pay-off of going it alone is then

$$
v(r, y)=\max _{s} u_{1}(y-s)+u_{2}(r s)
$$

where $r$ denotes the interest factor, and $s$ is money saved. Since saving is the only means of providing for old-age consumption, $s$ will never be negative.

As in standard life-cycle theory, go-it-aloners will then equate the marginal rate of substitution of present for future consumption to the interest factor,

$$
\frac{u_{1}^{\prime}(y-s)}{u_{2}^{\prime}(r s)}=r
$$

The effects of small changes in $(r, y)$ on the pay-off of the strategy are

$$
v_{r}(r, y)=s u_{2}^{\prime}(r s), v_{y}(r, y)=u_{1}^{\prime}(y-s)
$$

both positive. 


\subsection{Compliers}

Compliers have children, or there would be no point in complying. As they confidently expect to get filial support in old age, compliers may want to borrow from the market. That however, they are not allowed to do, because an entitlement arising from an informal arrangement like a family constitution is not legally transferable, and cannot thus be used as collateral. ${ }^{1}$ Therefore,

$$
s \geq 0,
$$

On the other hand, for reasons that will become apparent in a moment, selfish compliers have no interest in lending. Therefore, (6) will hold as an equation. Since selfish compliers do not make presents any more than selfish go-it-aloners do, (1) and (2) will hold as equations too.

If the children also comply, the pay-off for an agent with income $y$ of complying with a constitution that prescribes $(x, z)$ is

$$
v^{*}(p, x, y, z)=\max _{n} u_{1}(y-x-(p+z) n)+u_{2}(n x) .
$$

The agent's choice of $n$ satisfies

$$
\frac{u_{1}^{\prime}(y-x-(p+z) n)}{u_{2}^{\prime}(n x)}=\frac{x}{p+z} .
$$

Notice that the agent's marginal rate of substitution is equated to the marginal return of money spent on children. There is nothing to ensure that it will be also to the interest factor as in the go-it-aloner's case.

The effects of small changes in $(p, x, y, z)$ on the pay-off of complying are

$$
\begin{gathered}
v_{x}^{*}(p, x, y, z)=-u_{1}^{\prime}(y-x-(p+z) n)+n u_{2}^{\prime}(n x), \\
v_{y}^{*}(p, x, y, z)=u_{1}^{\prime}(y-x-(p+z) n), \\
v_{z}^{*}(p, x, y, z)=-n u_{1}^{\prime}(y-x-(p+z) n), \\
v_{p}^{*}(p, x, y, z)=-n u_{1}^{\prime}(y-x-(p+z) n) .
\end{gathered}
$$

Those of $p$ and $z$ are clearly negative. That of $y$ is clearly positive. That of $x$ is negative or positive according to whether the marginal rate of marginal substitution is higher or lower than $n$.

\subsection{Self-enforcing family constitutions}

Suppose that all (present and future) members of the same family are identical. Provided that

$$
v^{*}(p, x, y, z) \geq v(r, y),
$$

\footnotetext{
${ }^{1}$ Nothing of substance changes if we assume, instead, that they face a positive credit ration, lower than the cost of a child.
} 
complying with a family constitution that prescribes $(x, z)$ is then the best response to every other member of the family doing the same. The set of "comply" strategies (one for each member of the family) is thus a Nash equilibrium. Since complying implies threatening one's own parent of punishment if she does not comply too, and since the threat is credible, because carrying it out is in the interest of the person making it, the equilibrium is sub-game perfect. In equilibrium, the threat is never carried out because everybody complies.

For a complier, having a child is a form of investment, costing $(p+z)$ now, and yielding (in equilibrium) $x$ when she gets old. Since a complier must satisfy (2) irrespective of how many children she chooses to have, a necessary condition for (12) to be true is that

$$
\frac{x}{p+z}>r \text {. }
$$

Otherwise, there would be no way to recover the fixed cost of complying. That is indeed why a complier has no interest in saving. ${ }^{2}$

Figure 1 illustrates the properties of the set of constitutions that can be supported by a sub-game perfect Nash equilibrium. The set consists of all the $(x, z)$ pairs that satisfy $(12)$ given $(p, r, y)$. Since young children cannot make transfers, $z$ cannot be negative. It can be zero, however, because adults would be happy to subscribe to a constitution that does not oblige them to spend more than $p$ for each of their children. On the other hand, adults would not countenance a constitution that did not entitle them to receive transfers from the same children in the next period. Therefore, all points of the set satisfy

$$
z \geq 0, x>0
$$

The slope of the line segment joining $(-p, 0)$ to any point in the set is the marginal return to children implicit in the constitution represented by that point. The constitution with the highest marginal return is the one represented by point $\left(0, x^{m}\right)$.

The boundary of the set (the heavy line in Figure 1) is the locus of the $(x, z)$ pairs that satisfy $(12)$ as an equation. In view of $(8)-(10)$, the slope of the boundary is given by

$$
\frac{d z}{d x}=\frac{u_{2}^{\prime}(x n)}{u_{1}^{\prime}(y-x-(p+z) n)}-\frac{1}{n} .
$$

Since

$$
\frac{d^{2} z}{d(x)^{2}}=\frac{n u_{1}^{\prime} u_{2}^{\prime \prime}+u_{1}^{\prime \prime} u_{2}^{\prime}}{\left(u_{1}^{\prime}\right)^{2}}
$$

\footnotetext{
${ }^{2}$ Nothing of substance changes if we assume a positive credit ration, lower than the cost of a child.
} 
is clearly negative, $z$ is maximized at the point $\left(z^{*}, x^{*}\right)$, where $(14)$ is equal to zero. In view of (7), this implies

$$
n=\frac{x}{p+z}
$$

Although $v_{y}$ and $v_{y}^{*}$ are both positive in view of (5) and (9), a rise in $y$ would shift the boundary outwards, because the marginal rate of substitution is higher for compliers than for go-it-aloners in view of (4), (7) and (13). By contrast, a rise in $p$ or $r$ would shift the boundary inwards, because $v_{p}^{*}$ is negative in view of (11), and $v_{r}$ positive in view of (5). The probability of complying is thus increasing in $y$, and decreasing in $p$ and $r$.

\subsection{Renegotiation-proof family constitutions}

We have seen that a constitution satisfying (12) is self-enforcing in the limited sense that it is in every family member's interest to obey it, and have it obeyed. Given, however, that an infinite number of constitutions may have that property, what is there to stop every generation re-writing the rules to its own advantage? A constitution worth its name must not be amendable unless unforeseen circumstances make it unviable. In this section, we adapt the renegotiation-proofness concept developed by Bernheim and Ray (1989), and Maskin and Farrell (1989). In those papers, the players are always the same, and the constitution is thus supposed to regulate the way an individual behaves towards his contemporaries. Here, by contrast, the players change at each round, and the constitution is supposed to regulate the way present adults behave towards past and future ones.

Any generation can propose a new constitution. Will subsequent ones take any notice? Not if the old constitution (i) satisfies (12), and (ii) is not Pareto-dominated by any other constitution also satisfying (12). If the existing constitution is undominated, the only way a person can offer her children a better deal, and not loose in the bargain, is in fact to pay her parent less than the existing constitution requires - in other words, to default on the existing constitution. But that makes her liable to punishment at the hands of her own children, who will be better-off upholding the existing constitution, which entitles them to pay nothing to her, than acquiescing to the proposed new one. Once established, a constitution satisfying the double requirement of being a sub-game perfect Nash equilibrium, and undominated by any other constitution that is itself a sub-game perfect Nash equilibrium, is thus unamendable. Let us look at its properties. 
Selfish adults are interested only in their own adult and old-age consumption. As their children are interested in their entire lifetime consumption stream, however, a family constitution is renegotiation-proof if it maximizes

$$
V(n, x, z)=u_{0}(z)+u_{1}(y-x-(p+z) n)+u_{2}(x n),
$$

subject to (12). The first-order conditions are (16) and

$$
\frac{u_{0}^{\prime}}{u_{1}^{\prime}}=(1+\lambda) n=(1+\lambda) \frac{u_{1}^{\prime}}{u_{2}^{\prime}},
$$

where $\lambda$ is the Lagrange-multiplier of (12).

If $(12)$ is not binding $(\lambda=0)$, the parent equates her marginal rate of substitution of adult for old-age consumption to her children's marginal rate of substitution of childhood for adult consumption. The common value of these marginal rates is equal to the number of children, hence to the marginal return of money spent on them. If (12) is binding $(\lambda>0)$, the parent's marginal rate of substitution will still be set equal to the number of children, and thus to the marginal return of money spent on them, but lower than the children's marginal rate of substitution. In the first case, the renegotiation-proof constitution could be anywhere inside the Nash-frontier. In the second, it can only be at $\left(x^{*}, z^{*}\right)$, because that is the only point of the frontier satisfying (16). The only renegotiationproof constitution is in then the one that maximizes parental support for young children.

In Figure 1, the broken curves, with slope $\left(u_{0}^{\prime}-u_{1}^{\prime} n\right) /\left(-u_{1}^{\prime}+u_{2}^{\prime} n\right)$, are the contours of $V($.$) . The picture is drawn under the assumption$ that this function happens to reach a maximum just inside the Nash frontier, close to $\left(z^{*}, x^{*}\right)$. There is obviously no special reason why this should be the case. Since the Nash frontier shifts inwards as the interest rate rises, however, the probability that the solution is at, or close to, $\left(z^{*}, x^{*}\right)$ increases with $r$. Notice that the constitution which maximizes the marginal return to children, $\left(0, x^{m}\right)$, can never be renegotiationproof. $^{3}$

\subsection{Extensions: uncertainty and personal attention}

We now consider two important extensions of the non-altruistic model, beginning with uncertainty. Were it possible to make constitutional

\footnotetext{
${ }^{3}$ In a seminal paper, Browning (1975) makes the point that, since children do not vote, the pension system produced by a direct democracy will be larger than the one which maximizes the lifetime utility of the representative agent. At the family level, that is the same as saying that $z$ will be set at zero, and $x$ at the highest level compatible with Nash equilibrium. The role of a constitution is to prevent just that.
} 
prescriptions fully contingent, uncertainty would make no difference of substance to our story. Realistically assuming that drawing up a constitution accounting for all possible contingencies is prohibitively costly, however, investing in children will be risky. Assuming that it is riskier than investing in conventional assets, or that the two kinds of risk are uncorrelated, it may then be optimal for a complier to save and have children. In effects, uncertainty may thus induce agents to mix the comply and go-it-alone strategies. Apart from that, the predictions of the basic model remain unaltered. ${ }^{4}$

The other extension consists in allowing utility to depend only from market goods ("money"), but also on personal services ("attention") received from parents when the agent is young, children when she is old. For this to make any difference, it must also be true that money and attention are not perfect substitutes. The variable $c_{t}$ is now to be interpreted as the money equivalent of goods consumed and attention received, rather than just consumption expenditure, in period $t$. Constraint (1) is similarly to be interpreted as saying that a young person is entitled to receive from her parent goods and attention yielding at least the same utility as a sum of money $z$, and (2) as saying that an old person is entitled to receive from each of her children goods and attention yielding at least the same utility as a sum of money $x .^{5}$ As compliers will then give their elderly parent and young children the costminimizing combination of time and money, the enforceability condition (13) becomes easier to satisfy.

Introducing attention in the utility function has thus the effect of relaxing the Nash constraint, thereby raising the probability that an agent with given personal characteristics will comply. Intuitively, that is not only because complying is now less costly, but also and above all because the only way to get attention from one's own grown-up children is to comply. Another effect is that, as income is now endogenous, a wage rate rise need not shift the Nash frontier uniformly outwards as in the basic model. The frontier associated with a higher wage rate may now cross the one associated with a lower wage rate.

\section{The model with altruistic agents}

Introspection and casual observation suggests that parents may be altruistic towards their children. But, does altruism make a difference to the way people actually behave in the presence of self-enforcing family constitutions? If the answer were no, we could not tell whether a person

\footnotetext{
${ }^{4}$ Rosati (1996) demonstrates this for the case where the uncertainty concerns a child's survival to adult age.

${ }^{5}$ See Cigno and Rosati (2000).
} 
observed making transfer to her mother and children is doing that out of her own good heart, or because it is in her own interest. If the answer were yes, would it still make sense to talk of self-enforcing constitutions? To answer these questions we introduce altruism as in Becker and Barro (1988). Like those authors, and many others after them, we thus assume that altruism flows from parents to children, not the other way round. This may seem rather extreme, but nothing of substance would change if we assumed, instead, that people are more altruistic towards their children, than towards their parents.

For simplicity of exposition, we revert to assuming certainty, and that parental and filial attention have perfect market substitutes. A person's lifetime utility is now taken to be given by

$$
U=u_{0}\left(c_{0}\right)+u_{1}\left(c_{1}\right)+u_{2}\left(c_{2}\right)+\beta U^{*}\left(m_{0}, m_{1}\right) n, 0<\beta<1,
$$

where $U^{*}\left(m_{0}, m_{1}\right)$ stands for a child's lifetime utility maximized subject to the transfers $\left(m_{0}, m_{1}\right)$ that she received from her parent. The function $U^{*}($.$) is increasing and concave. The parameter \beta$ is a measure of parental altruism.

\subsection{Altruistic go-it-aloners}

Unlike a selfish one, an altruistic go-it-aloner may choose to have children, and to make transfers to them. As the children will not reciprocate when they become adult, and will not accept a negative bequest, the goit-aloner's choice of $m_{1}$ must satisfy

$$
n m_{1} \geq 0
$$

As the agent cannot rely on her children for old-age support, $s$ will still be positive as in the non-altruistic case. It thus remains true that a go-it-aloner cannot be credit rationed.

The pay-off to going it alone is now

$$
\begin{aligned}
v(p, r, y)= & \max _{\left(m_{0}, m_{1}, n, s\right)} u_{1}\left(y+m_{-1}-s-\left(p+m_{0}\right) n\right)+u_{2}\left(s r-n m_{1}\right) \\
& +\beta U^{*}\left(m_{0}, m_{1}\right) n, \text { s.t. }(19),
\end{aligned}
$$

where $m_{-1}$ is the amount (nonnegative like $m_{1}$ ) that the agent inherited from her own parent.

The choice of $\left(m_{0}, m_{1}, n, s\right)$ associated with this strategy satisfies

$$
\frac{u_{1}^{\prime}\left(y+m_{-1}-s-\left(p+m_{0}\right) n\right)}{u_{2}^{\prime}\left(s r-n m_{1}\right)}=r=\frac{\beta U_{0}^{*}}{\beta U_{1}^{*}+v}
$$


and

$$
\frac{\beta U^{*}\left(m_{0}, m_{1}\right)}{u_{1}^{\prime}\left(y+m_{-1}-s-\left(p+m_{0}\right) n\right)}=p+m_{0}+\left(1-\frac{v}{u_{2}^{\prime}\left(s r-n m_{1}\right)}\right) \frac{m_{1}}{r},
$$

where $v$ is the Lagrange-multiplier of (19).

Condition (20) says that, if the agent is rich or altruistic enough $\left(y+m_{-1}\right.$ or $\beta$ high enough) for $(19)$ to be slack $(v=0)$, the parent's and children's marginal rates of substitution of present for future consumption will be equalized, and the common value of these two marginal rates set equal to the interest factor. If $m_{1}$ is at a corner $(v>0)$, the parent's marginal rate of substitution will still be equated to the interest factor, but the children's will be higher. Condition (21) tells us that, if (19) is slack, she will have children to the point where the marginal benefit, $\frac{\beta U^{*}}{u_{1}^{\prime}}$, equals to the marginal cost, $\left(p+m_{0}+\frac{m_{1}}{r}\right)$. Otherwise, she will have more.

The effects of small changes in $(p, r, y)$ on the pay-off of going it alone are now

$$
\begin{gathered}
v_{p}(p, r, y)=-n u_{1}^{\prime}\left(y+m_{-1}-s-\left(p+m_{0}\right) n\right) \\
v_{r}(p, r, y)=s u_{2}^{\prime}\left(s r-n m_{1}\right)
\end{gathered}
$$

and

$$
v_{y}(p, r, y)=u_{1}^{\prime}\left(y+m_{-1}-s-\left(p+m_{0}\right) n\right) .
$$

Those of $r$ and $y$ have the same sign as in the non-altruistic model. That of $p$ is clearly negative.

\subsection{Altruistic compliers}

Unlike a selfish one, an altruistic complier may choose to give each of her children more than $z$ when they are young, and accept less than $x$ from each of them when they become adults. Indeed, an altruistic complier may choose to bequeath each child a sum larger than $x$, thus making $m_{1}$ positive. Therefore, (1) need not hold as an equation as in the nonaltruistic model. The same applies, in principle, also to (2). If that were the case, however, the element of threat that makes a constitution sustainable as a sub-game perfect Nash equilibrium would be missing. For the constitution to be an effective restriction on behaviour, (2) must thus hold as an equation.

It remains true that an agent cannot borrow against transfers she expects to receive from her children when she gets old. We will show in a moment, however, that a complier may want to do some positive saving. Therefore, (6) is not necessarily a binding as in the model without 
altruism. For an altruistic agent, the pay-off of complying is

$$
\begin{aligned}
v^{*}(p, r, x, y, z)= & \max _{\left(m_{0}, n\right)} u_{1}\left(y+m_{-1}-s-x-\left(p+m_{0}\right) n\right)+u_{2}(s r+n x) \\
& +\beta U^{*}\left(m_{0},-x\right) n, \text { s.t. }(1),(6) .
\end{aligned}
$$

The altruistic complier's choice of $\left(m_{0}, n, s\right)$ satisfies

$$
\begin{gathered}
u_{1}^{\prime}\left(y-x-s+\left(p+m_{0}\right) n\right)=\beta U_{0}^{*}\left(m_{0},-x\right)+\zeta \\
\frac{u_{1}^{\prime}\left(y-x-s-\left(p+m_{0}\right) n\right)-\sigma}{u_{2}^{\prime}(s r+n x)}=r
\end{gathered}
$$

and

$$
\frac{\beta U^{*}\left(m_{0},-x\right)}{u_{1}^{\prime}\left(y-x-s-\left(p+m_{0}\right) n\right)}=p+m_{0}-\frac{u_{2}^{\prime}(s r+n x)}{u_{1}^{\prime}\left(y-x-s-\left(p+m_{0}\right) n\right)} x,
$$

where $\zeta$ and $\sigma$ are the Lagrange multipliers of, respectively, (1) and (6).

According to $(25)$, if $m_{0}$ is not at a corner $(\zeta=0)$, the agent will reduce the amount transferred to each young child to the point where the marginal utility that she altruistically derives from the child's current consumption equals the marginal utility that she selfishly derives from her own current consumption. Otherwise $(\zeta>0)$, she will give each young child exactly $z$. In view of $(26)$, if $s$ is not at a corner $(\sigma=0)$, the agent will reduce her saving to the point where her marginal rate of substitution of present for future consumption equals the interest factor. Otherwise $(\sigma>0)$, she will save nothing. In either case, there is nothing, at this stage, to ensure that marginal rates of substitution are equalized.

If we re-write (27) as

$$
\frac{u_{1}^{\prime}\left(y+m_{-1}-s-x-\left(p+m_{0}\right) n\right)}{u_{2}^{\prime}(s r+n x)}=\left(1+\frac{\beta U^{*}\left(m_{0},-x\right)}{u_{2}^{\prime}(s r+n x) x}\right) \frac{x}{p+m_{0}},
$$

and compare it with (26), it becomes clear that an altruistic agent may comply even if the marginal return to money spent on children is no higher than the interest factor. Indeed, if credit is not effectively rationed $(\sigma=0), \frac{x}{p+m_{0}}$ will be lower than $r$. The reason is, of course, that for an altruistic complier the benefit of an extra child is greater than $x$. If credit is effectively rationed $(\sigma>0)$, the marginal return will then be higher than the interest factor as in the model without altruism. Otherwise, the two will be equalized, and the complier will do some positive saving.

In view of (27), the agent will again have children to the point where the marginal benefit is equal to the marginal cost. If (1) is not binding, the right-hand side of (27) is clearly lower than that of (21).We can 
then be sure that the agent will has more children if she complies, than if she goes it alone. The same may happen if $m_{0}$ is held at $z$, but not necessarily. The level of $z$ could in fact be so high, that it more than compensates for the negative value of $m_{1}$ (equal to $-x$ ), especially (1) if (6) also is binding, and the agent thus discounts $m_{1}$ at more than the interest rate.

The effects of small changes in $(p, x, y, z)$ on the pay-off of complying are

$$
\begin{gathered}
v_{p}^{*}(p, r, x, y, z)=-n u_{1}^{\prime}\left(y+m_{-1}-s-x-\left(p+m_{0}\right) n\right), \\
v_{r}^{*}(p, r, x, y, z)=s u_{2}^{\prime}(s r+n x), \\
v_{x}^{*}(p, r, x, y, z)=-u_{1}^{\prime}\left(y+m_{-1}-s-x-\left(p+m_{0}\right) n\right)+n u_{2}^{\prime}(s r+n x)-n \beta U_{1}^{*}\left(m_{0},-x\right), \\
v_{y}^{*}(p, r, x, y, z)=u_{1}^{\prime}\left(y+m_{-1}-s-x-\left(p+m_{0}\right) n\right)
\end{gathered}
$$

and

$$
v_{z}^{*}(p, r, x, y, z)=-n \zeta .
$$

Those of $p$ or $r$ are, respectively, negative and positive. That of $x$ is negative if the agents's marginal rate of substitution is no lower than $n$. Otherwise, it may be positive. ${ }^{6}$ That of $z$ is negative if $m_{0}$ is at a corner, zero otherwise. ${ }^{7}$

\subsection{Self-enforcement and renegotiation-proofness un- der altruism}

A constitution prescribing $(x, z)$ is now a subgame-perfect Nash equilibrium if and only if

$$
v^{*}(p, r, x, y, z) \geq v(p, r, y) .
$$

In view of (26) and (35), this implies

$$
\left(1+\frac{\beta U^{*}\left(m_{0},-x\right)}{u_{2}^{\prime}(s r+n x) x}\right) \frac{x}{p+m_{0}}>r .
$$

Therefore, $\frac{x}{p+m_{0}}$ need not be greater than $r$, as in the non-altruistic model.

The slope of the Nash boundary is now given by

$\frac{d z}{d x}=-\frac{u_{1}^{\prime}\left(y+m_{-1}-s-x-\left(p+m_{0}\right) n\right)-n u_{2}^{\prime}(s r+n x)+n \beta U_{1}^{*}\left(m_{0},-x\right)}{n \zeta}$.

\footnotetext{
${ }^{6}$ May, rather than will as in the model without altruism, because $x$ now reduces the altruistic component of the agent's utility.

${ }^{7}$ In the model without altruism, $m_{0}$ is always at a corner.
} 
If (1) is not binding $(\zeta=0)$, the boundary is thus a straight line, perpendicular to the $x$ axis. In that case, there is no trade-off between $z$ and $x$. If $(1)$ is binding $(\zeta>0)$, the boundary has the same shape as in the non-altruistic model (see Figure 1), but $z$ is now maximized where

$$
\frac{u_{1}^{\prime}\left(y+m_{-1}-s-x-\left(p+m_{0}\right) n\right)}{u_{2}^{\prime}(s r+n x)}=\left(1-\frac{\beta U_{1}^{*}\left(m_{0},-x\right)}{u_{2}^{\prime}(s r+n x)}\right) n .
$$

In view of (26), (6) and (37), it is thus not true that, at the point where $z$ reaches a maximum, $n$ is necessarily greater than $r$ as in the model without altruism. That will be true only if saving is not at a corner $(\sigma=0)$. Intuitively, that is because the agent can then increase her current consumption by saving less, rather than by having fewer children. In view of $(20),(22),(24),(26),(29),(30)$ and (32), the effects of $p, r$ and $y$ on the probability of complying are qualitatively the same as in the non-altruistic model. It thus remains true that a rise in $p$ or $r$ reduces this probability that a self-enforcing family constitution exists, while a rise in $y$ increases it.

Assuming that $\beta$ is small enough to make $\beta n$ less than unity, ${ }^{8}$ otherwise the optimization would be unbounded, a renegotiation-proof constitution now maximizes

$$
W(n, x, z)=\frac{u_{0}\left(m_{0}\right)+u_{1}\left(y-x-s-\left(p+m_{0}\right) n\right)+u_{2}(s r+n x)}{1-\beta n},
$$

subject to (1), (6) and (34).

Consider first the case where (1) is not binding, and $v_{z}^{*}(p, r, x, y, z)$ is consequently equal to zero. The solution then satisfies $(26),(27)$,

$$
\frac{u_{0}^{\prime}\left(m_{0}\right)}{u_{1}^{\prime}\left(y-x-\left(p+m_{0}\right) n\right)}=n
$$

and

$$
\frac{u_{1}^{\prime}\left(y+m_{-1}-s-x-\left(p+m_{0}\right) n\right)}{u_{2}^{\prime}(s r+n x)}=n+\mu(1-\beta n) \frac{v_{x}^{*}(p, r, x, y, z)}{u_{2}^{\prime}(s r+n x)},
$$

\footnotetext{
${ }^{8}$ In a stationary environment, we shall then have that

$u_{0}\left(m_{0}\right)+u_{1}\left(y-x-s-\left(p+m_{0}\right) n\right)+u_{2}(s r+n x)+\beta U^{*}\left(m_{0},-x\right) n$ $=(1+\beta n)\left[u_{0}\left(m_{0}\right)+u_{1}\left(y-x-s-\left(p+m_{0}\right) n\right)+u_{2}(s r+n x)\right] n+\beta^{2} n^{2} U^{*}\left(m_{0},-x\right)$

$=\frac{u_{0}\left(m_{0}\right)+u_{1}\left(y-x-s-\left(p+m_{0}\right) n\right)+u_{2}(s r+n x)}{(1-\beta n)}$
} 
where $\mu$ is the Lagrange multiplier of (34)

If $(1)$ is binding, and $v_{z}^{*}(p, r, x, y, z)$ consequently negative, the solution satisfies (26), (27),

$$
\frac{u_{0}^{\prime}(z)}{u_{1}^{\prime}(y-x-(p+z) n)}=\left(1-\mu(1-\beta n) \frac{v_{z}^{*}}{u_{1}^{\prime}(y-x-(p+z) n)}\right) n
$$

and

$$
\frac{u_{1}^{\prime}\left(y+m_{-1}-s-x-(p+z) n\right)}{u_{2}^{\prime}(s r+n x)}=n+\mu(1-\beta n) \frac{v_{x}^{*}(p, r, x, y, z)}{u_{2}^{\prime}(s r+n x)} .
$$

It is thus clear that, irrespective of whether the credit rationing constraint is binding or not, a renegotiation-proof constitution equalizes the marginal rates of substitution of parent and children if only if the Nash constraint on the choice of constitution, $(34)$, is not binding $(\mu=0) .{ }^{9}$ If that is the case, the common value of the two marginal rates of substitution is equal to $n$. If the Nash constraint is binding $(\mu>0)$, the parent's marginal rate of substitution is lower than the children's, implying that $v_{x}^{*}(p, r, x, y, z)$ is negative. For the opposite to be true, $v_{x}^{*}(p, r, x, y, z)$ would in fact need to be positive. In view of (31), however, that would imply that the parent's marginal rate of substitution is lower than $n$, thus contradicting both (39) and (41).

Depending on whether the renegotiation-proof constitution lies inside or on the Nash frontier, a complier's marginal rate of substitution will thus be either equal to, or higher than her children's. Both propositions were true also in the model without altruism. Altruism does make some difference however. First, if the credit ration is not binding $(\sigma=0), n$ is equal to $r$ in view of (26). In the model without altruism, by contrast, the credit ration was always tight, and $n$ always higher than $r$. Second, if the Nash constraint is binding $(\mu>0)$, and $z$ is relevant $(\zeta>0)$, the renegotiation-proof constitution cannot be at the point of the Nash frontier where $z$ is maximized as in the absence of altruism, because the right-hand side of (37) is lower than the right-hand side of (41). The constitution in question will lie further down the frontier, where both $z$ and $x$ are lower, and the parent's marginal rate of substitution lower too.

\section{Efficiency}

We shall now inquire whether individual choice, with or without family constitutions, brings about an efficient allocation. But, what does

\footnotetext{
${ }^{9}$ If (6) is binding, however, the common value of the two marginal rates of substitution is higher than $r$.
} 
efficient mean in an endogenous fertility context? The Pareto criterion allows us to compare different allocations of goods to the same collection of individuals. It cannot thus be applied in a context like the present one, where the existence of future adults depends on decisions taken by the present ones. We can use, however, the quasi-Pareto criterion proposed by Baland and Robinson (2002).

According to those authors, an allocation $\mathbf{A}$ is deemed Pareto-preferred to an allocation $\mathbf{B}$ if both the utility of the parent, and the average utility of the children, are higher in $\mathbf{A}$ than in $\mathbf{B}$. The reference to an average level of utility leaves the door open for the possibility that the number of children associated with $\mathbf{A}$ is different from the one associated with B. Assuming that children are (a) born sequentially, and (b) equally treated by their parents, this allows us to step into the middle of an agent's reproductive career, and ask if there exists a contract between her and the children born up to that moment, that would induce the former to curtail her fertility plans.

In the non-altruistic version of the model, only compliers have children. We have seen that the parent's and the children's marginal rates of substitution are equalized if and only if (12) is slack. Otherwise, the parent will value her current consumption, at the margin, more than her children value theirs. The situation is illustrated in Figure 2, where the convex-to-the origin curves describe a child's intertemporal preferences. The children's marginal rate of substitution is equal to $\delta$. That of the parent is equal to $\gamma$, lower than $\delta$. The parent's utility maximizing plan is to have $\gamma$ children, and allocate her resources so that each child receives $c_{0}^{B}$ units of money-equivalent consumption now, and consumes $c_{1}^{B}$ in adult life. It is clear that any child would be happy to trade $\left(c_{1}^{B}-c_{1}^{A}\right)$ units of future, for $\left(c_{0}^{A}-c_{0}^{B}\right)$ of present consumption.

If such a contract were enforceable, the parent would be indifferent between carrying out her initial plan, or having

$$
n^{A} \equiv \frac{p+c_{0}^{B}}{p+c_{0}^{A}} \gamma<\gamma
$$

children, and allocating her resources so that each child consumes gets $c_{0}^{A}$ now, and $c_{1}^{A}$ in the future. Any number of children lower than $n^{A}$ would make the parent and each of those children better-off. This makes the original plan inefficient in the Baland-Robinson sense. As a child cannot credibly commit to pay a parent more than $x$, however, the deal will not go through. The parent can then do no better than have $\gamma$ children, each consuming $c_{0}^{B}$ now, and $c_{1}^{B}$ in the next period. Fertility will consequently be inefficiently high, and the amount consumed by each 
young child inefficiently low. ${ }^{10}$ The necessary and sufficient condition for the allocation brought about by a renegotiation-proof family constitution to be efficient is then that the Nash constraint is not binding.

In the altruistic model, not only compliers, but also go-it-aloners may have children. If a go-it-aloner is rich and altruistic enough for (19) to be slack, she sets her marginal rate of substitution equal to her children's. Otherwise, she will set it lower. She will then have an inefficiently high number of children, and give each of them an inefficiently low level of consumption while young. The necessary and sufficient condition for an altruistic go-it-aloner to behave efficiently is thus that the nonnegative bequests constraint is not binding. ${ }^{11}$ What about altruistic compliers? If (34) is slack, a renegotiation-proof family constitution equalizes the parent's and the children's marginal rates of substitution. ${ }^{12}$ Otherwise, the parent's marginal rate of substitution will be higher than the children's, fertility will be inefficiently high, and youthful consumption will be inefficiently low. As in the non-altruistic model, the necessary and sufficient condition for the allocation brought about by a renegotiationproof constitution to be efficient is thus that the Nash constraint is not binding.

\section{Behavioural and policy implications}

Granted that self-enforcing and renegotiation-proof family constitutions may exist, what difference does that make to the way individuals respond

\footnotetext{
${ }^{10}$ Taking fertility as exogenous, and interpreting $z$ as educational investment, Anderberg and Balestrino (2003) show that, if the Nash constraint is binding, the renegotiation-proof constitution is inefficient in the usual Pareto sense. Under their assumptions, this implies that investment in the children's education, rather than the children's current consumption, will be too low.

${ }^{11}$ The first to remark that "operative bequests" are necessary for an altruistic agent unconstrained by a family constitution to behave efficiently are Becker and Murphy (1988). But, those authors were thinking of efficiency in the standard Pareto sense, which is not applicable in an endogenous fertility context. Baland and Robinson (2002) show that the proposition remains true if one applies their own quasi-Pareto criterion, which is compatible with endogenous fertility. They consider also the possibility that the credit rationing constraint is stringent. But, we have argued that this cannot be, because a go-it-aloner will want to save for old age, not borrow, all the more so if she proposes to leave bequests.

${ }^{12}$ Since an altruistic complier may be credit rationed, the common value of the marginal rates of substitution could be higher than the interest factor, but that would not make the allocation inefficient in the Baland-Robinson sense. A binding credit ration would be a source of inefficiency if the parent were a go-it-aloner, because there would then be no constitution to equate her marginal rate of substitution to that of her children. But go-it-aloners are never credit rationed, because they do not want to borrow.
} 
to a change in the economic environment? ${ }^{13}$ Recall that an agent may respond by either adjusting what variables she can under the present strategy, or by switching strategies. In this section, we examine the effects of two environmental changes with a direct bearing on intergenerational transfers, the introduction of a mandatory pension system, and a tightening of the credit ration. Throughout, we shall assume that agents differ only in their income. Since an increase in current income raises the pay-off of complying more than the pay-off of going it alone, we can then find a threshold level of income, $y^{m}$, such that an agent will comply if, and only if, she is at or above the threshold. A small rise in $y^{m}$ will cause agents at the threshold to switch from comply to go-it-alone. A small reduction will cause agents just below the threshold to switch the other way. We shall call an agent who switches strategies a marginal player.

\subsection{Pensions}

Consider the effects of introducing or expanding a pension system that requires each adult to pay $\tau$, and entitles each old person to receive $\pi$. In order to isolate the effects of compulsory old-age insurance from those of any implicit pension tax or subsidy, ${ }^{14}$ we assume that the scheme is actuarially fair. In our certainty framework, this simply means

$$
\pi=r \tau
$$

We further assume that $\tau$ is no higher than the amount that go-it-aloners would save without the policy. This implies that only compliers can be credit rationed. In view of (42), the wealth position of go-it-aloners is thus unaffected by the policy. By contrast, the policy leaves nonaltruistic compliers worse-off, because it forces them to pay more into a public scheme that, in view of (13), yields a lower marginal return than the family one. In view of (35), the same is not necessarily true of altruistic compliers. If these agents are not credit rationed, their wealth position is unaffected.

We start by assuming that agents are not altruistic. The pay-off of

\footnotetext{
${ }^{13}$ Given the (subjective) certainty framework we have adopted here, we are obviously talking of an unexpected change. In an uncertainty framework, the prescriptions contained in the constitution would be contingent on the the state of the economic environment. If all contingencies were contemplated, it would then make no sense to talk of unexpected changes. It would, however, if we realistically assume that the cost of drawing up a fully contingent constitution is prohibitively high.

${ }^{14}$ The implicit pension tax is defined as the difference, at the date of retirement, between the capitalized value of the contributions, and the expected value of the benefits; see Sinn (1990).
} 
the go-it-alone strategy is now

$$
v(r, y, \tau)=\max _{s}\left[u_{1}(y-\tau-s)+u_{2}((s+\tau) r)\right] .
$$

As the policy does not alter their wealth position, inframarginal go-italoners have no reason to change their life plans. As it lowers their demand for old-age consumption, however, it induces them reduce their saving by the amount of the extra pension contribution,

$$
\frac{d s}{d \tau}=-1
$$

Their fertility and transfers remain zero.

The effect $y$ on the pay-off of going it alone,

$$
v_{y}(r, y, \tau)=u_{1}^{\prime}(y-\tau-s),
$$

remains positive. That of $\tau$,

$$
v_{\tau}(r, y, \tau)=-u_{1}(y-\tau-s)+r u_{2}((s+\tau) r),
$$

is zero in view of (4).

The pay-off of the comply strategy is now

$$
v^{*}(p, x, y, z, \tau)=\max _{n}\left[u_{1}(y-\tau-x-(p+z) n)+u_{2}(n x+r \tau)\right] .
$$

Although the policy reduces their demand for old-age consumption, inframarginal compliers cannot respond by saving less, because their saving is already zero. As their transfer behaviour is prescribed by the constitution, and their fertility is fixed by (16), all that will change is then their utility. Using (16), the effect of $y$ on the pay-off of the strategy,

$$
v_{y}^{*}(p, x, y, z, \tau)=u_{1}^{\prime}(y-\tau-2 x),
$$

remains positive. That of $\tau$,

$$
v_{\tau}^{*}(p, x, y, z, \tau)=-u_{1}^{\prime}(y-\tau-2 x)+\left(r-\frac{x}{p+z}\right) u_{2}^{\prime}\left(\frac{x^{2}}{p+z}+r \tau\right),
$$

is negative in view of (13).

The threshold level of income below which agents go it alone solves

$$
v^{*}(p, x, y, z, \tau)=v(r, y, \tau) .
$$

Since $v_{y}^{*}\left(p, x^{m}, y^{m}, z^{m}, \tau\right)$ is larger than $v_{y}\left(r, y^{m}, \tau\right)$ in view of (4), (7) and (13), and having established that (47) is negative,

$$
\frac{d y^{m}}{d \tau}=-\frac{v_{\tau}^{*}\left(p, x^{m}, y^{m}, z^{m}, \tau\right)}{v_{y}^{*}\left(p, x^{m}, y^{m}, z^{m}, \tau\right)-v_{y}\left(r, y^{m}, \tau\right)}
$$


is positive. The policy thus raises the threshold, thereby inducing marginal players to switch from the comply to the go-it-alone strategy. These agents will stop having children and making transfers, and will start saving.

It is thus clear that, in a selfish world, the policy has non-positive effects on the fertility and private transfers of all inframarginal players, and negative ones on those of marginal players. Aggregate fertility will consequently fall, and some of the old will be left without filial support. The effect on saving is non-positive where inframarginal players are concerned. But marginal players will be induced to save more. If there are enough of the latter, the policy will thus raise aggregate saving. This is in sharp contrast with the prediction of standard life-cycle theory.

Let us now introduce altruism. As compliers and go-it-aloners alike may now have children, make transfers, and save, the pay-off of going it alone is

$$
\begin{aligned}
v(p, r, y, \tau)= & \max _{\left(m_{0}, m_{1}, n, s\right)} u_{1}\left(y-\tau+m_{-1}-s-\left(p+m_{0}\right) n\right)+u_{2}\left((s+\tau) r-n m_{1}\right) \\
& +\beta U^{*}\left(m_{0}, m_{1}\right) n, \text { s.t. }(19) .
\end{aligned}
$$

As in the non-altruistic model, inframarginal go-it-aloners will not change their consumption, fertility and transfer plans in response to the policy. They will just save less. The effect of $y$ on the pay-off of the strategy,

$$
v_{y}(p, r, y, \tau)=u_{1}^{\prime}\left(y-\tau+m_{-1}-s-\left(p+m_{0}\right) n\right),
$$

is again positive. That of $\tau$,

$v_{\tau}(p, r, y, \tau)=-u_{1}^{\prime}\left(y-\tau+m_{-1}-s-\left(p+m_{0}\right) n\right)+r u_{2}^{\prime}\left((s+\tau) r-n m_{1}\right)$,

is zero in view of $(26)$.

The pay-off of the comply strategy is

$$
\begin{aligned}
v^{*}(p, r, x, y, z)= & \max _{\left(m_{0}, n\right)} u_{1}\left(y-\tau+m_{-1}-s-x-\left(p+m_{0}\right) n\right)+u_{2}((s+\tau) r+n x) \\
& +\beta U^{*}\left(m_{0},-x\right) n, \text { s.t. }(1),(6) .
\end{aligned}
$$

If the credit ration is not binding, inframarginal compliers will respond to the policy like inframarginal go-it-aloners. They will just save less. If (6) is binding, however, the policy will make them poorer, and there will then be income effects. Compliers will in that case reduce $n$ and, if it is not effectively constrained by (1), $m_{0}$. If they cannot reduce $m_{0}$, because (1) is binding, they will reduce $n$ even more. Their saving will stay zero. The effect of $y$ on the pay-off of the policy,

$$
v_{y}^{*}(p, r, x, y, z, \tau)=u_{1}^{\prime}\left(y-\tau+m_{-1}-s-x-\left(p+m_{0}\right) n\right),
$$


is positive as usual. In view of (26), the effect of $\tau$, $v_{\tau}^{*}(p, r, x, y, z, \tau)=-u_{1}^{\prime}\left(y-\tau+m_{-1}-s-x-\left(p+m_{0}\right) n\right)+r u_{2}((s+\tau) r+n x)$,

is zero if credit is not effectively rationed, negative otherwise.

In the presence of altruism, $y^{m}$ satisfies

$$
v^{*}\left(p, r, x^{m}, y^{m}, z^{m}, \tau\right) \equiv v\left(p, r, y^{m}, \tau\right) .
$$

The effect of the policy on the threshold level of income,

$$
\frac{d y^{m}}{d \tau}=-\frac{v_{\tau}^{*}\left(p, r, x^{m}, y^{m}, z^{m}, \tau\right)}{v_{y}^{*}\left(p, r, x^{m}, y^{m}, z^{m}, \tau\right)-v_{y}\left(p, r, y^{m}, \tau\right)},
$$

is positive or zero depending on whether marginal players would, or would not, be credit rationed if they complied. In the first case, the policy induces marginal players to switch from the comply to the go-it-alone strategy. The behavioural implications are then qualitatively the same as in the model without altruism. Aggregate fertility will fall, aggregate saving may rise or fall, some of the old will loose their children's support. In the second case, nobody will change strategy. Aggregate fertility will then again fall. But aggregate saving would definitely fall, and no old person would lose her children's support because of the policy.

Altruism, therefore, does not alter the proposition that a wealthpreserving expansion in mandatory pension coverage will reduce aggregate fertility, and may raise aggregate saving. This proposition is in sharp contrast with the prediction of the Becker-Barro model (and of our model where altruistic go-it-aloners are concerned) that the policy will induce agents to save less, and will have no effect on their fertility and transfer behaviour because it does not entail an intergenerational transfer. There is some evidence that, if the intergenerational transfer implied by a deficit or surplus in the pension fund budget is controlled for, pension coverage has a nonnegative effect on aggregate household saving, and a negative one on aggregate fertility. ${ }^{15}$

\subsection{Credit rationing}

We now turn to the implications of a reduction in the credit ration. To do that, we must allow the ration to be positive in the first place, rather than zero as we have assumed so far. For example, in the presence of a public pension scheme like the one considered in the last subsection, we might assume that agents are allowed to borrow up to some fraction of $\tau$. We shall then re-write the credit rationing constraint as

$$
s \geq-b,
$$

\footnotetext{
${ }^{15}$ See, for example, Cigno and Rosati (1996), Cigno et al. (2002).
} 
where $b$ is a nonnegative number.

Start again by assuming that agents are not altruistic. The pay-off of the go-it-alone strategy is now

$$
v\left(b, r, y_{1}, y_{2}\right)=\max _{s}\left[u_{1}\left(y_{1}-s\right)+u_{2}\left(y_{2}+r s\right)\right], \text { s.t. }(54),
$$

where $y_{t}$ denotes income in period $t(t=1,2)$. If $y_{2}$ is sufficiently high, the agent may want to borrow. If (54) is binding, a reduction in the credit ration will then reduce the amount borrowed, and consequently the agent's utility. The effect on the pay-off of going it alone, given by

$$
v_{b}\left(b, r, y_{1}, y_{2}\right)=-\xi_{g}
$$

where $\xi_{g}$ is the Lagrange-multiplier of (54) given that the agent has adopted this strategy, is negative. That of a small change in current income,

$$
v_{y_{1}}\left(b, r, y_{1}, y_{2}\right)=u_{1}^{\prime}\left(y_{1}-s\right),
$$

is positive as usual.

The pay-off of the comply strategy is

$v^{*}\left(b, p, r, x, y_{1}, y_{2}, z\right)=\max _{(s, n)}\left[u_{1}\left(y_{1}-s-x-(p+z) n\right)+u_{2}\left(y_{2}+r s+n x\right)\right]$, s.t.

Here too, if (54) is binding, a reduction in the credit ration will reduce both the amount borrowed and the utility of inframarginal go-it-aloners. Their transfers behaviour will remain the same, but their fertility will fall (an income effect). The effect on the pay-off of the strategy, given by

$$
v_{b}^{*}\left(b, p, r, x, y_{1}, y_{2}, z\right)=-\xi_{c},
$$

where $\xi_{c}$ is the Lagrange-multiplier of (54) given that the agent has adopted this strategy, is negative. That of a small change in current income,

$$
v_{y_{1}}^{*}\left(b, p, r, x, y_{1}, y_{2}, z\right)=u_{1}^{\prime}\left(y_{1}-s-x-(p+z) n\right),
$$

is positive as usual.

The threshold level of current income, $y_{1}^{m}$, is now determined by

$$
v^{*}\left(b, p, r, x^{m}, y_{1}^{m}, y_{2}^{m}, z^{m}\right)=v\left(b, r, y_{1}^{m}, y_{2}\right) .
$$

The effect of $b$ on $y^{m}$ is given by

$$
\frac{d y^{m}}{d b}=-\frac{\xi_{g}-\xi_{c}}{v_{y}^{*}\left(b, p, r, x^{m}, y_{1}^{m}, y_{2}^{m}, z^{m}\right)-v_{y}\left(b, r, y_{1}^{m}, y_{2}\right)} .
$$


Leaving aside the case where the borrowing constraint is not binding whichever the strategy, and thus irrelevant, there are two possibilities. One is that (54) is binding whichever the strategy. Since $\xi_{g}$ is then equal to $v_{y}^{*}$, and $\xi_{c}$ to $v_{y},(59)$ is equal to -1 . The other is that (54) is binding only in the go-it-alone strategy, ${ }^{16}$ in which case (59) is more negative than in the last case. In either case, tighter credit rules would induce agents just below the income threshold to switch from going it alone to complying. These agents will start having children, and making transfers.

Introducing altruism makes a little difference. If marginal players are credit rationed whichever strategy they choose, a tighter ration will still induce them to switch from the go-it-alone to the comply strategy (if they are credit constrained in only one strategy, we cannot tell). They will thus transfer more. If their transfers are not at a corner, inframarginal players will transfer less.

The constitution model with or without altruism thus predicts that a reduction in the amount that can be borrowed may induce some agents to make more transfers despite the fact that they are now poorer. If altruism is absent or low, inframarginal players will not change their transfer behaviour, or will change it very little. Controlling for the possible endogeneity of the credit ration, Cigno et al. (2004) find evidence that the probability of making transfers to children increases if the parent is credit rationed. That cannot be explained by conventional models of either the altruistic or the exchange variety.

\section{Discussion}

Portraying the family as a society governed by a constitution, rather than as a purely affective relationship, enriches the economic analysis of fertility, saving and transfer behaviour. It also narrows the gap between the sociologist's stance, that individual actions as socially determined, and the economist's approach, which assumes unfettered individual choice. But we did not simply assume that there are exogenously determined constraints on individual behaviour. We derived conditions for the existence of a self-enforcing, renegotiation-proof family constitution prescribing that an adult must give at least a certain amount of money (or its utility equivalent in personal services) to her parent, and to each of her children if she has any.

For a constitution to be self-enforcing, adults must be at least as welloff obeying its rules, and causing others to do the same, as disobeying

\footnotetext{
${ }^{16}$ It is not possible for the borrowing constraint to be binding only in the comply strategy because, on any given indifference curve, the marginal rate of substitution is always higher if the agent complies than if she goes it alone.
} 
them. For it to be renegotiation-proof, the adults of the day must have no interest in re-writing the constitution. Parental altruism makes it more likely that a constitution with these characteristics will exist. But, if an agent is so rich and altruistic that she wants to give her children (now that they are young, and again later when they are adults) more than the constitution prescribes, the constitution is obviously irrelevant.

A renegotiation-proof family constitution generates an efficient allocation of resources if and only if the condition for it to be self-enforcing is not a binding constraint on the choice of constitution. The intuitive explanation is that, since the agents are adults, who will become old, but will not be young again, the requirement than an agent must not be worse-off complying than going it alone conflicts, if it is binding, with the requirement that the lifetime utility of each individual must be at a maximum given everyone else's lifetime utility. If the self-enforcement requirement is binding, the agent will have too many children, and each child will consume too little while young. Parental altruism makes no difference to that.

If an agent is so rich and altruistic that the constitution does not impose any effective restriction on her behaviour, she will not necessarily behave efficiently. As already pointed out by Baland an Robinson in relation to the Becker-Barro model, the allocation will in that case be efficient if and only if neither the credit rationing, nor the nonnegative bequests constraint is binding. Since the second of these constraints is more restrictive than the constitutional prescription that net transfers to a grown-up child must be at least equal to the negative of the transfers that the latter must make to the agent, the possible irrelevance of the family constitution does not make efficiency any more likely.

Exogenous changes in the economic environment may affect individual behaviour in two ways, (a) by changing the decision whether to adopt the comply or the go-it-alone strategy, and (b) by changing the choice of fertility, saving and transfer behaviour associated with each strategy. The former applies only to marginal players, agents whose income is just high enough to make them want to comply in the absence of policy. The latter applies to both marginal and inframarginal players. We have looked at the effects of two environmental changes, the introduction or expansion of an actuarially fair pension scheme, and a tightening of the credit ration.

In the absence of parental altruism, the pension policy has nonpositive effects on the fertility and private transfers of all inframarginal players, and negative ones on those of marginal players. Some old people would consequently lose their children's support. The effect on individual saving is non-positive where inframarginal players are concerned, 
positive where marginal players are. The effect on aggregate fertility is thus definitely negative, but the effect on aggregate saving may be positive or negative. This prediction is in sharp contrast with the one of standard life-cycle theory, that the policy would definitely discourage saving. Parental altruism makes some difference in other respects, but does not change the proposition that introducing or expanding a public pension scheme may actually raise aggregate saving.

Whether the agents are altruistic towards their children or not, a reduction in the amount they are allowed to borrow may induce some of them to have more children, and make larger transfers. This prediction contrasts with those of conventional models of either the altruistic or exchange variety.

These results may come as a surprise to anyone who is used to thinking in terms of infinitesimal adjustments of the decision variables to infinitesimal changes in the exogenous ones. In a model where the first and most important decision is about which strategy to follow, however, it is perfectly natural that the discreet changes associated with a strategy switch will dominate infinitesimal within-strategy adjustments. We have chosen the pension policy and credit rationing examples advisedly because, in both cases, the signs of some of the changes implied by a strategy switch are the opposite of those implied by an adjustment without change of strategy.

\section{$7 \quad$ References}

Anderberg, D. and A. Balestrino (2003), Self-Enforcing Transfers and the Provision of Education, Economica 70, 55-71

Baland, J. M. and A. Robinson (2002), Rotten Parents, Journal of Public Economics 84, 341-356

Becker, G. S. and R. J. Barro, 1988, A Reformulation of the Economic Theory of Fertility, Quarterly Journal of Economics 103, 1-25 and K. M. Murphy (1988), The Family and the State,

Journal of Law and Economics 31, 1-18

Bernheim, B. D. and D. Ray (1989), Collective Dynamic Consistency in Repeated Games, Games and Economic Behavior 1, 295-326

Cigno, A. (1993), Intergenerational Transfers Without Altruism: Family, Market and State, European Journal of Political Economy 9, 505-518 , Casolaro, L. and F. C. Rosati (2002), The Impact of Social Security on Saving and Fertility in Germany, FinanzArchiv 59, 189-211

—, Giannelli, G. C., Rosati, F. C. and D. Vuri (2004), Is There Such a Thing as a Family Constitution? A Test Based on Credit Rationing, IZA Discussion Paper $\mathrm{N}^{\circ} 1116$

and F. C. Rosati (1996), Jointly Determined Saving and 
Fertility Behaviour: Theory, and Estimates for Germany, Italy, UK, and USA, European Economic Review 40, 1561-1589

and F. C. Rosati (2000), Mutual Interest, Self-Enforcing Constitutions and Apparent Generosity, in L. A. Gérard-Varet, S.C. Kolm and J. Mercier Ythier (eds.), The Economics of Reciprocity, Giving and Altruism, London and New York: MacMillan and St. Martin's Press, 2000

Duesenberry, J. (1960), Comment on G. Becker, "An Economic Analysis of Fertility", in NBER Demographic and Economic Change in Developed Countries, Princeton: Princeton University Press

Guttman, J. M. (2001), Self-Enforcing Reciprocity Norms and Intergenerational Transfers, Journal of Public Economics 81, 117-151

Maskin, E. and J. Farrell (1989), Renegotiation in Repeated Games, Games and Economic Behavior 1, 327-360

Rosati, F. C. (1996), Social Security in a Non-Altruistic Model with Uncertainty and Endogenous Fertility, Journal of Public Economics 60, 283-294

Shubick, M. (1981), Society, Land, Love or Money, Journal of Economic Behavior and Organization 6, 359-385

Sinn, H. W. (1990), Korreferat zum Referat von K. Jaeger, in B. Gahlen, H. Hesse and H. J. Ramser (eds.), Theorie und Politik der Sozialversicherung, Tübingen: Mohr-Siebeck 


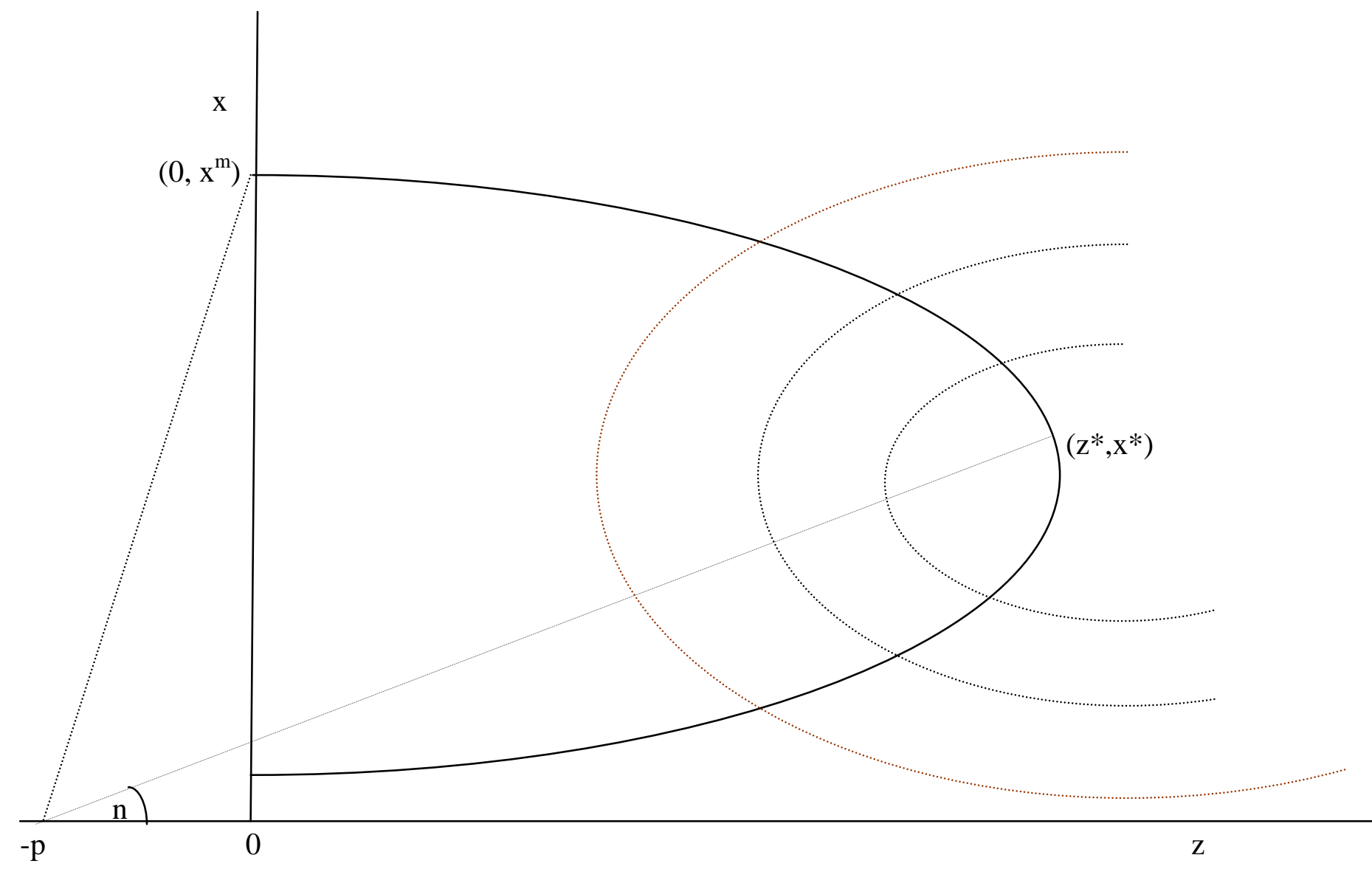

Figure 1: The Nash-frontier and the renegotiation-proof family constitution. 


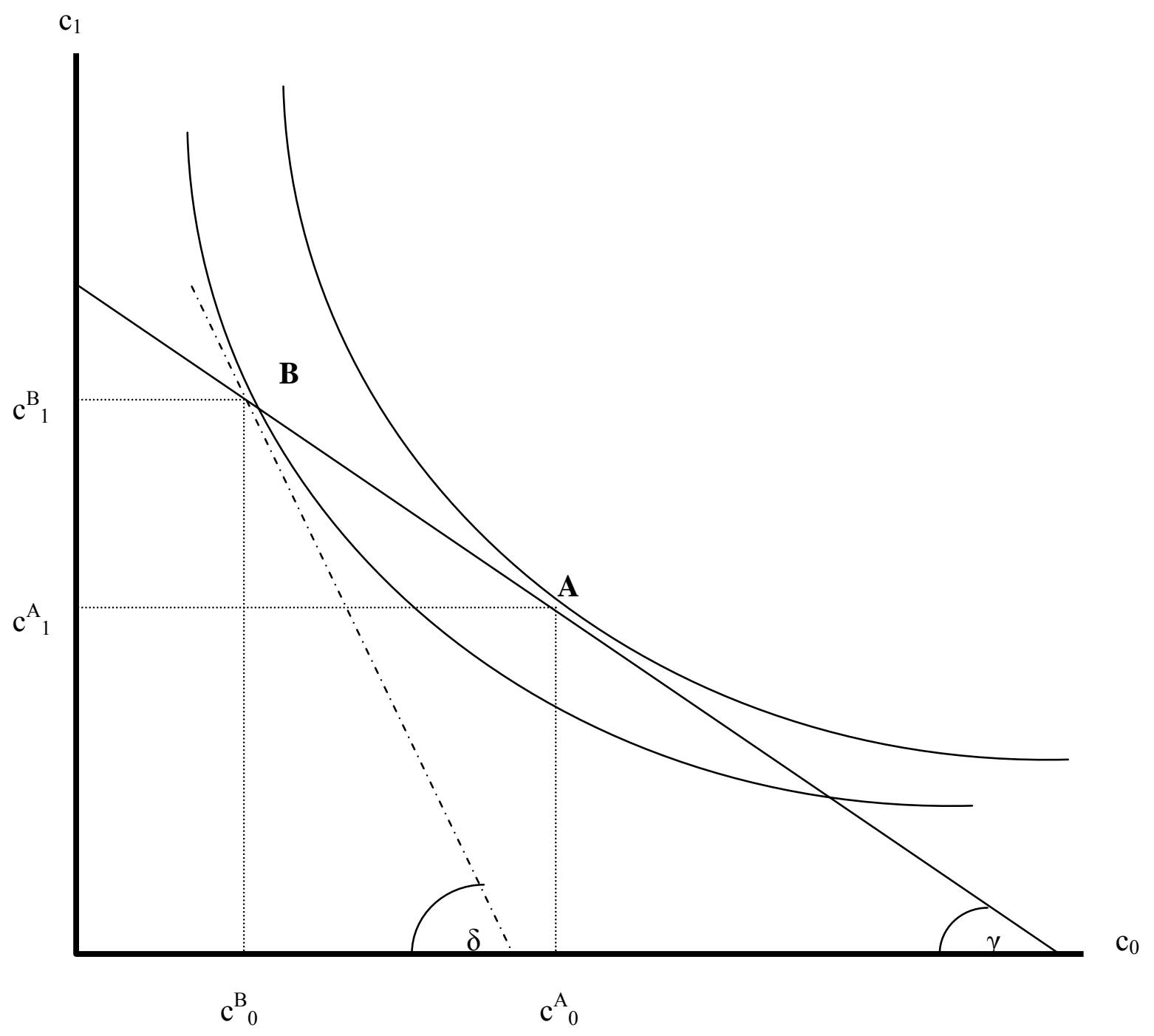

Figure 2: The effect of a binding Nash constraint. 